\title{
Fracture analysis for lubricating oil pipe of compressor
}

\author{
Jun SI, Huating LV, Facai REN \\ Shanghai Institute of Special Equipment Inspection and Technical Research, Shanghai, 200062
}

\begin{abstract}
The rupture analysis of lubricating oil pipe has been conducted through chemical composition analysis, metallographic analysis and fracture analysis. The analysis results show that there are machining defects and bidirectional vibration at the joint of lubricating oil pipe, which leads to fatigue fracture.
\end{abstract}

\section{Introduction}

In the pressure transmission system, mechanical vibration and noise are produced due to the reciprocating nature of the compressor working process in the system. Under the action of cyclic load, the original defects or manufacturing defects of pipelines in the system are prone to fatigue fracture failure, which may lead to the leakage of transmission materials and pollute the environment, or even cause system damage and casualties. Structural failure often occurs in industrial production due to mechanical vibration [1-6].

The lubricating oil pipe of compressor in a chemical

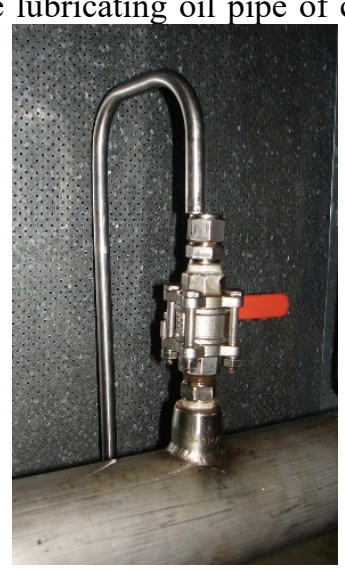

plant has broken after one year of operation. The construct material of the oil pipe is ASTM 316L stainless steel, and the medium in the pipeline is lubricating oil. In order to find out the cause of the fracture of the lubricating oil pipe, the failure analysis was carried out in this paper.

\section{Macroscopic examination}

Fracture macroscopic morphology of lubricating oil pipe is shown in Fig. 1. Both ends of the oil pipe have the same structure, which are conical pipes. The fracture location of the lubricating oil pipe occurs within the clamp on one side and there is no significant plastic deformation at the fracture location.
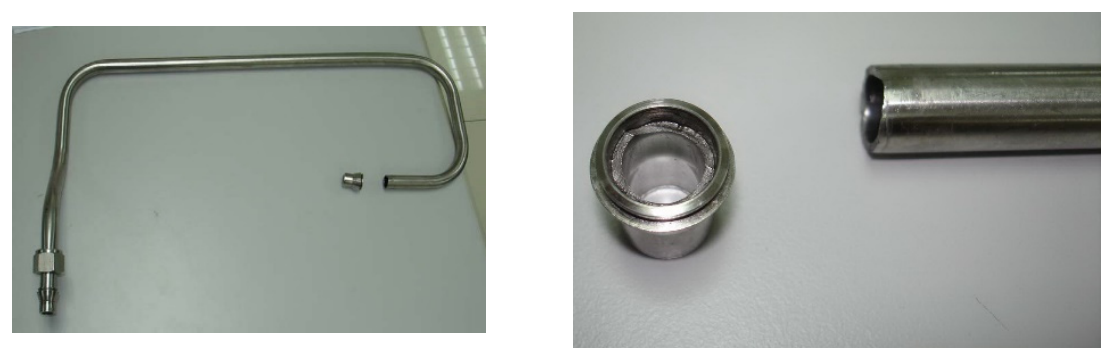

Fig 1. Fracture morphology of lubricating oil pipe

\section{Chemical component analysis}

Chemical composition analysis was performed on the material of the broken lubricating oil pipe, and the analysis results were compared with the requirements of ASTM 316L material, as shown in Table 1. The results show that the material conforms to the requirement of $316 \mathrm{~L}$ stainless steel composition stipulated in ASTM standard, and the possibility of fracture caused by wrong material selection is excluded. 
Table1. Comparison of chemical composition analysis results (w\%)

\begin{tabular}{ccccccccc}
\hline element & $\mathrm{C}$ & $\mathrm{Si}$ & $\mathrm{Mn}$ & $\mathrm{S}$ & $\mathrm{P}$ & $\mathrm{Cr}$ & $\mathrm{Ni}$ & $\mathrm{Mo}$ \\
\hline $\begin{array}{c}\text { measured } \\
\text { value }\end{array}$ & 0.019 & 0.56 & 1.73 & 0.010 & 0.029 & 17.77 & 12.87 & 2.15 \\
$\begin{array}{c}\text { the value in } \\
\begin{array}{c}\text { ASTM 316L } \\
\text { standard }\end{array}\end{array}$ & $<0.030$ & $<1.00$ & $<2.00$ & $<0.030$ & $<0.045$ & $16.0 \sim 18.0$ & $10.0 \sim 14.0$ & $2.00 \sim 3.00$ \\
\hline
\end{tabular}

\section{Fracture analysis}

Overall macroscopic features of the fracture of lubricating oil pipe are shown in Fig.2. The external surface characters at the location of fracture is shown in the Fig.2a, and the origin of the crack is lie in the conical position constructed of the lubricating oil pipe. There are deep machining grooves in the part of A side, but there is no

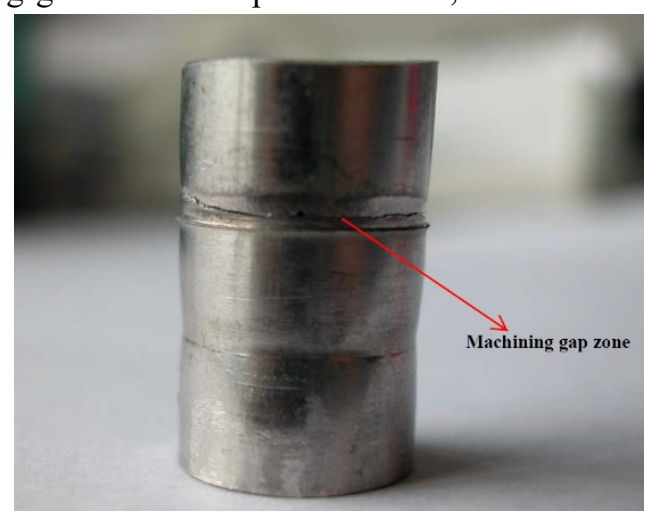

trace of such redundant machining in other parts along the circumference direction. The macro morphology of the section of fracture is shown in the Fig. $2 \mathrm{~b}$. It can be seen from Fig. $2 b$ that both sides of $A$ and $B$ are the initiation positions of crack growth, and the cracks propagate towards the centers of the section of the oil pipe. The direction of arrow in Fig.2b shows the direction of crack propagation.

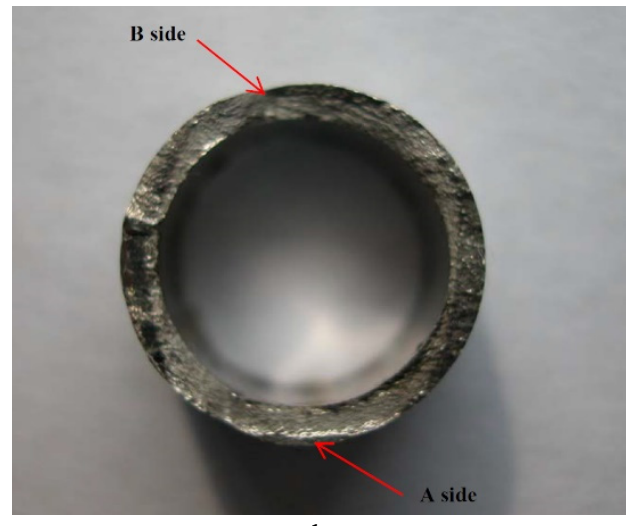

Fig 2. Macro morphology of the surface and section of the broken lubricating oil pipe

The section of fracture of A and B sides was analyzed by Scanning Electron Microscopy (SEM), as shown in Fig. 3 and Fig.4. It can be seen from the Fig. 3 and Fig. 4 that there are obvious fatigue striations on the fracture surfaces on both sides of $\mathrm{A}$ and $\mathrm{B}$, so the broken reason of the oil pipe can be judged as fatigue fracture. The length of fatigue crack propagation in A side is longer than that in B side. With the propagation of fatigue crack, the material strength is not enough to bear the pressure and the instantaneous fracture occurs finally. Since there are two initiation zones in the section of oil pipe, it can be judged that there is bidirectional vibration for the oil pipe in the process of service. The schematic diagram of fracture process simulated is shown in Fig. 5

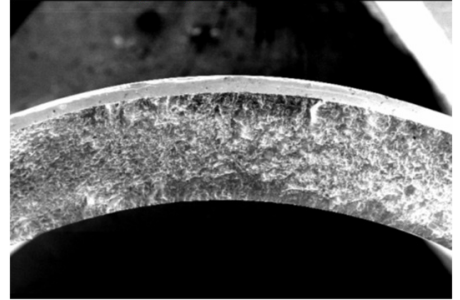

$\times 20$

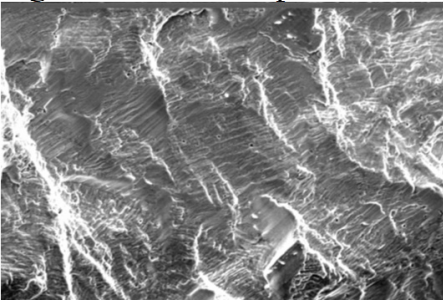

$\times 500$

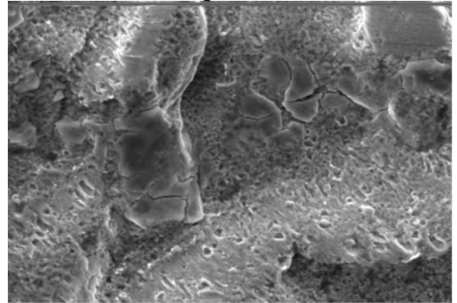

$\times 1000$

Fig 3. Scanning electron microscopy (SEM) of the fracture on A side

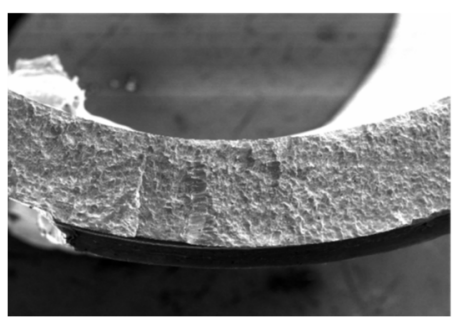

$\times 20$

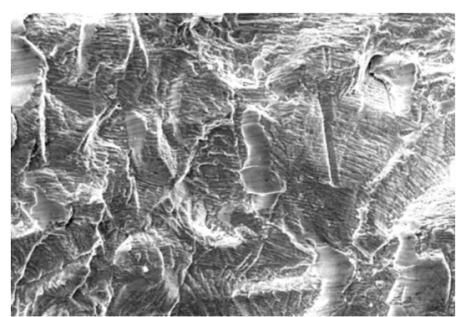

$\times 500$

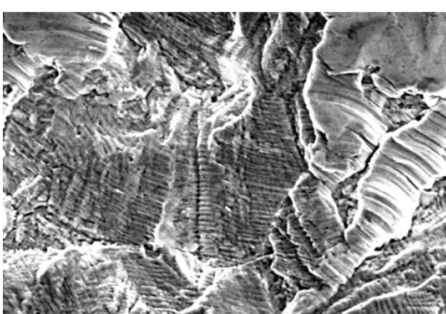

$\times 1000$

Fig 4. Scanning electron microscopy (SEM) of the fracture on B side 


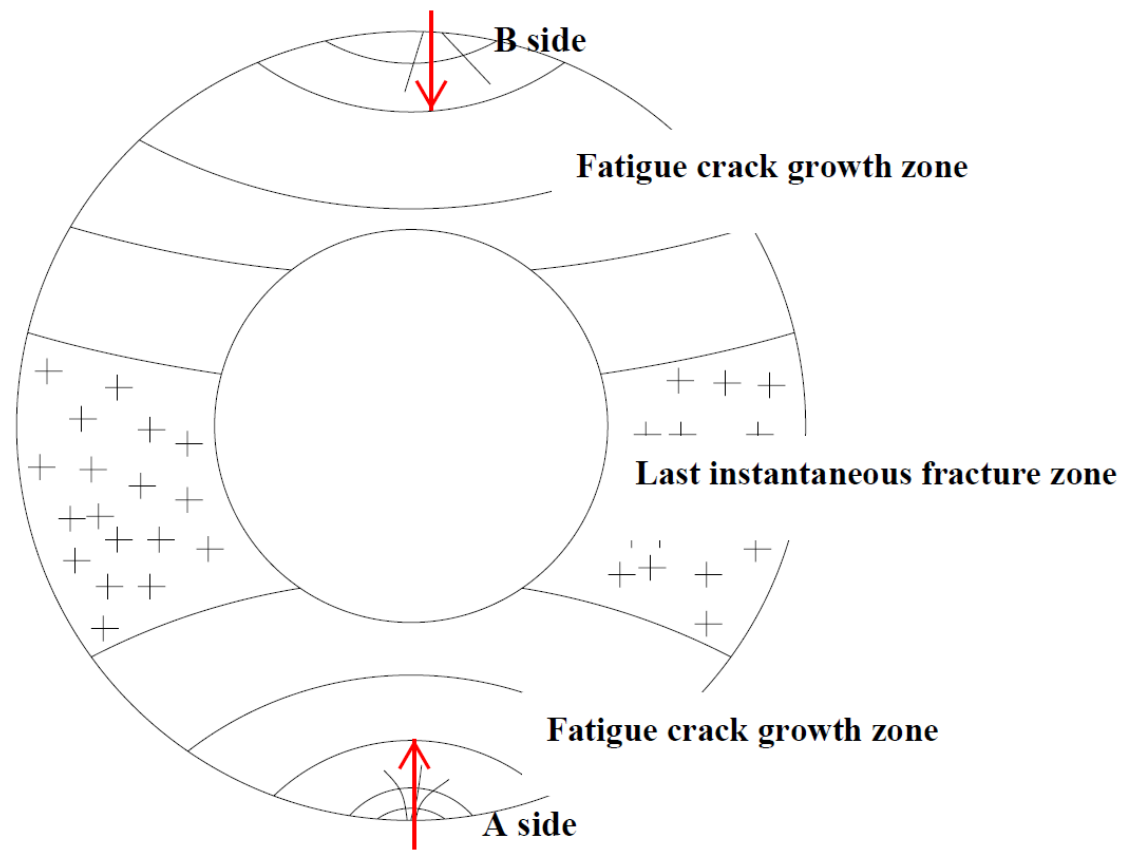

Fig 5. The schematic diagram of fracture process simulated fracture location was analyzed. It can be seen from the

\section{Metallographic analysis of materials} figure that the metallographic structure of the oil pipe was normal, which was single-phase austenite structure, as

The metallographic structure of the sample taken from the shown in Fig. 6.

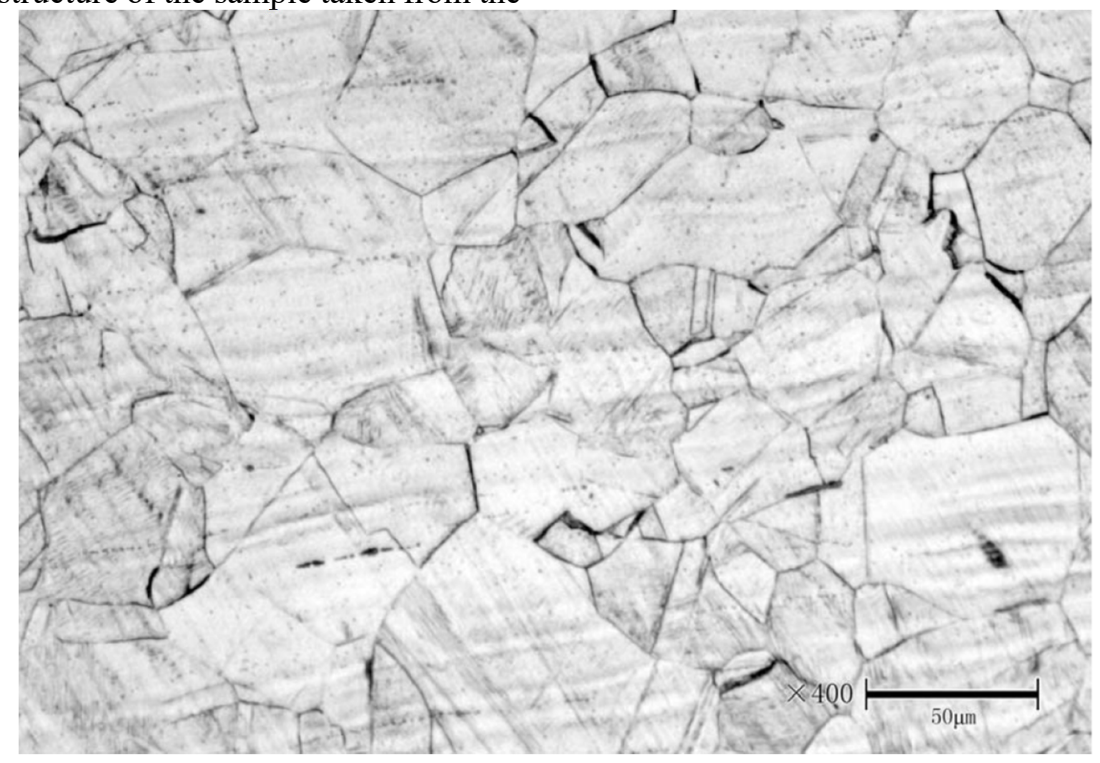

Fig 6. Metallographic structure of lubricating oil pipe

\section{Conclusion and recommendation}

The analysis shows that the failure mode of the lubricating oil pipe is fatigue fracture. The conical structure of the lubricating oil pipe is over machined, which leads to discontinuity of structure and stress concentration at the position machined. At the same time, there is the bidirectional vibration phenomenon at the conical position of the oil pipe during operation. Under the action of vibration, cracks are firstly initiated at the over machined part of the conical position. With the initiation of the crack here, the crack also occurs on the opposite side, and then the crack gradually expanded, and finally the instantaneous fracture occurs. Therefore, the fracture of lubricating oil pipe is mainly caused by fatigue under machining defects and external vibration conditions.

It is suggested that the machining quality should be improved and measures should be taken to reduce fluid the induced vibration of fluid. 


\section{Reference}

1. ZHOU Shuai, REN Yanping, LIU Bing, LI Weidong, HE Wenyun. Study on Acceleration Load Spectrum Editing of Diesel Engine's High-pressure Fuel Pipes, Noise and Vibration Control, 2018, 38 (4): 34-38, 44.

2. LIU Jian, SONG Xi-ping. Failure analysis on $0 \mathrm{Cr} 18 \mathrm{Ni} 9$ stainless steel oil tube in a power plant. Heat Treatment of Metals, 2007, 32 (12): 103-105.

3. Xie Liang, Fan Feng, Ma Xiaofeng, Shang Haikun. Fault Analysis of Cracks Occured in Multi Branch Lubricating Oil Pipe System Based on Finite Element Analysis. Diesel Engine, 2016, 38 (4): 40-42, 49.

4. PENG Jiazheng, CHEN Wei, QIU Kangyong, ZHANG Jie. Fracture Failure Analysis of a HeatTransfer Oil Pipe, Physical Testing and Chemical Analysis Part B: Chemical Analysis, 2017, 53 (11): 837-840.

5. ZHU Jian, LI Xiao. Fatigue Characteristics Study and Fracture Analysis of CT80 Coiled Tubing, Hot Working Technology, 2018, 47 (10): 259-262.

6. CUI Xu-ming, HE Fu-jun, ZHANG Jing, LUO Min. Fatigue Strength Analysis of Oil Tube, Journal of Experimental Mechanics, 2004, 19 (1): 72-78. 